\title{
Effect of a perspective-taking intervention on the consideration of pain assessment and treatment decisions
}

\author{
This article was published in the following Dove Press journal: \\ Journal of Pain Research \\ II November 2015 \\ Number of times this article has been viewed
}

Objectives: Pain is often poorly managed, highlighting the need to better understand and treat patients' pain. Research suggests that pain is assessed and treated differently depending on patient sex, race, and/or age. Perspective-taking, whereby one envisions the perspective of another, has been found to reduce racial disparities in pain management. This study used virtual human $(\mathrm{VH})$ technology to examine whether a perspective-taking intervention impacts pain management decisions.

Methods: Ninety-six participants were randomized to an online treatment or control group and viewed 16 video clips of VHs with standardized levels of pain. Participants provided ratings on the VHs' pain intensity and their willingness to administer opioids to them. The intervention group received a brief perspective-taking intervention that consisted of having participants imagine how the patient's suffering could affect his/her life, whereas the control group was asked to wait for the next VH videos to load. A LENS model analysis was used to investigate both group level (nomothetic) and individual level (idiographic) decision policies. A LENS model of analysis is typically used as an analog method for capturing how groups of people and individuals use information in their environment to form judgments.

Results: Nomothetic results found that participants rated pain higher and were more likely to prescribe opioids to VHs postintervention, irrespective of group. Idiographic results, however, found that the use of cues to make pain management decisions was mitigated by the perspectivetaking group. The participants in the perspective-taking group were more likely to think about pain and the patients' perspective during the intervention, while control participants were more likely to reflect on the VHs' sex, race, or age.

Conclusion: A brief intervention may alter participants' pain management decisions. These results indicate that a brief intervention might be an initial step toward aligning observers' pain management ratings with those of the patient. Future research is needed to replicate findings in a health care population.

Keywords: pain management, perspective taking, virtual technology

\section{Introduction}

Although pain affects a large percentage of the US population, most chronic pain conditions are poorly understood and inadequately managed. ${ }^{1}$ Previous research has found that the pain management (assessment and treatment) decisions of laypeople, health care trainees, and health care professionals are affected by patients' sex, race, and age..$^{2-6}$ Research also has found that pain management decisions which are based on sex, race, and age can lead to disparities in pain management. For example, women as well as ethnic and racial minorities are more likely to receive less aggressive pain treatment (ie, lower receipt of opioid analgesics) than their demographic counterparts. ${ }^{7-9}$ Research also
Correspondence: Michael E Robinson University of Florida, I0I South Newell Drive, Gainesville, FL 32610-9165, USA Tel +I 3252735220

Fax +I 3522736156

Emailmerobin@ufl.edu 
has found that older adults often have their pain undertreated and underidentified, relative to younger adults. ${ }^{6,10,11}$ Therefore, it is important to find ways for health care professionals and laypeople to better understand the pain sufferer's experience so that pain management strategies can be improved.

The National Pain Strategy ${ }^{12}$ stresses the importance of not only educating health care professionals about best pain management strategies, but also of educating laypeople. Thus, it is necessary to have a better understanding of not only how health care professionals and health care trainees assess and treat pain, but also how laypeople assess and treat pain. Understanding health care professionals, health care trainees, and laypeople's pain management decisions is vital because each group will, to varying degrees, assess and treat pain complaints (eg, assessing and treating patients, caring for loved ones, coaching athletes, evaluating one's own pain experience).

Some research has examined how perspective-taking, a cognitive-based intervention that encourages one to take on the perspective of another by imagining how the other's suffering could affect his/her life, can improve health care professionals' treatment practices. ${ }^{13,14}$ By encouraging one to imagine how another individual's suffering could affect his/her life, perspective-taking increases empathy. ${ }^{15}$ Initial research suggests that a perspective-taking model could improve health care professionals' treatment of patients by helping them understand their patients' health experience. ${ }^{13,14}$ For instance, Drwecki et $\mathrm{al}^{14}$ found that a brief perspective-taking intervention could change participants' pain ratings. In that study, undergraduate students and nurses were found to have negative pain treatment biases toward African-Americans compared to Caucasians. However, after participating in a brief perspective intervention, both the undergraduate students and nurses were able to reduce the disparities in their pain treatment ratings by $55 \%$. These changes in ratings were attributed to the undergraduate students and nurses being able to adopt the patient's perspective.

New research indicates that virtual technology is being used to provide education and trainings to health care trainees and providers. ${ }^{16,17}$ Research also has begun to examine whether medical students demonstrate nonverbal communication behaviors and respond empathetically to virtual humans (VHs). Although the quantity and quality of the behaviors were less than that with a real patient, empathy was still observed with VH patients. Previous VH studies also report using $\mathrm{VH}$ technology because the facial features and pain expressions can be standardized on the VH images, which eliminates bias associated with other confounding factors (eg, patient's socioeconomic status). ${ }^{18}$

Thus, a novel way of implementing a perspective-taking intervention is through the use of VH technology. Previous studies have used online virtual technology to examine the facial pain expressions of VHs and have found that participants' pain management decisions differed depending on the VHs' demographic characteristics (sex, race, and age). ${ }^{18-21}$ However, previous VH studies have never examined the use of perspective-taking as a potential intervention to examine participants' pain management decisions. Previous VH research also has found that the type of medical providers that the participants are (eg, dentists, physicians, or nurses) influences providers' pain management decisions and their use of demographic characteristics to make pain management decisions. ${ }^{19,22,23}$ In light of these findings, interventions aimed at reducing pain-related treatment disparities are warranted, and the findings from this study could be used for educating medical students and health care providers in the future.

The purpose of this study was threefold: 1) assess the efficacy of a $\mathrm{VH}$ perspective-taking intervention on pain management decisions; 2) determine whether demographic characteristics of the $\mathrm{VH}$ influence pain management ratings; and 3) investigate whether participants' intervention-related cognitions during the study (both the perspective-taking and the control group) impacted the participants' pain management decisions.

\section{Methods}

\section{Procedures/design}

This study was approved by the Institutional Review Board of the University of Florida. Participants were recruited via flyers posted around the University of Florida campus. The study used an online web-based delivery model. Participants were asked to read an informed consent that described the study. If the participants agreed to participate in the study, the provided electronic consent. Participants were then randomized to either the control or perspective-taking group. Figure 1 describes the study's procedures.

\section{Patient profiles}

Participants observed two sets of eight VH profiles (Figure 2), each consisting of a 20-second looped video. The order of the $\mathrm{VH}$ profiles was randomized. In each video, $\mathrm{VH}$ images were composed of three cues: sex (female vs male), race (white vs black), and age (younger adult vs older adult). All of the VHs expressed high pain behaviors. These expressions were determined through the use of an empirically validated method (Facial Action Coding System or "FACS"), whereby four FACS units (ie, brow lowering, tightening of the orbital muscles, nose wrinkling/upper lip raising, and eye closure) were identified based upon commonly expressed pain behaviors. ${ }^{24} \mathrm{VH}$ technology was utilized because facial 


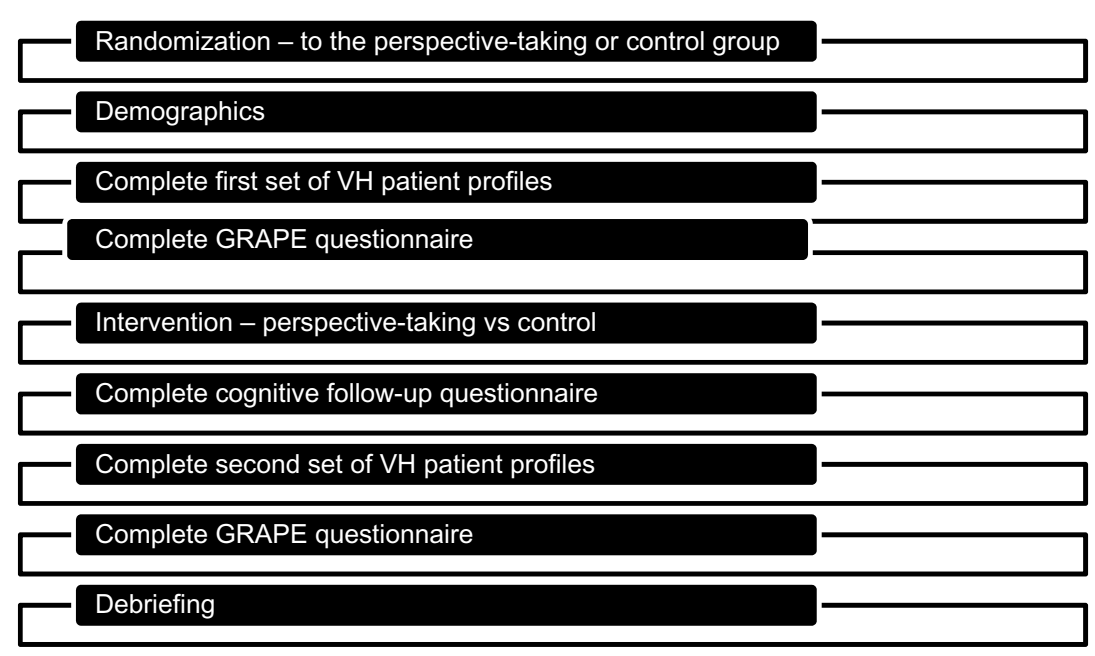

Figure I Study procedure.

Abbreviations: GRAPE, Gender, Race, and Age Pain Expectations questionnaires; VH, virtual human.

features and pain expressions can be standardized, which eliminates bias associated with other confounding factors (eg, patient's socioeconomic status).

For each of the profiles, all of the participants read the same clinical vignette:

Patient presents with lower back pain for the past year. Patient reports that the pain began after a work-related lifting incident. The pain is located in the lumbar region of the back. The pain limits patient's ability to move around freely. Patient reports no prior surgical treatments and has current prescriptions for anti-inflammatory medications.

\section{Intervention and control groups}

The participants were engaged in either the control or perspective-taking task. If they were in the control group, they read:

Please wait two minutes while the next set of videos load. (A timer will count down two minutes at the bottom of the webpage).

If they were in the perspective-taking group, they read:

Imagine how your patient feels when healthcare professionals rate his/her chronic pain. Imagine what the patient is feeling as if you were the patient, experiencing the world as he or she does. When you see your chronic pain patient, imagine how your patient is feeling when you are considering whether to prescribe opioid medication. Imagine what the patient is feeling as if you were the patient, experiencing the world as he or she does.

All of the participants were then asked to write what they were thinking about during the control and perspectivetaking tasks.

\section{Participants}

Of the 96 participants who completed this study, approximately $60 \%$ were female, $65 \%$ were Caucasian, $69 \%$ were non-Hispanic, and $96 \%$ were single. The average age of the participants in this study was 20.6 years

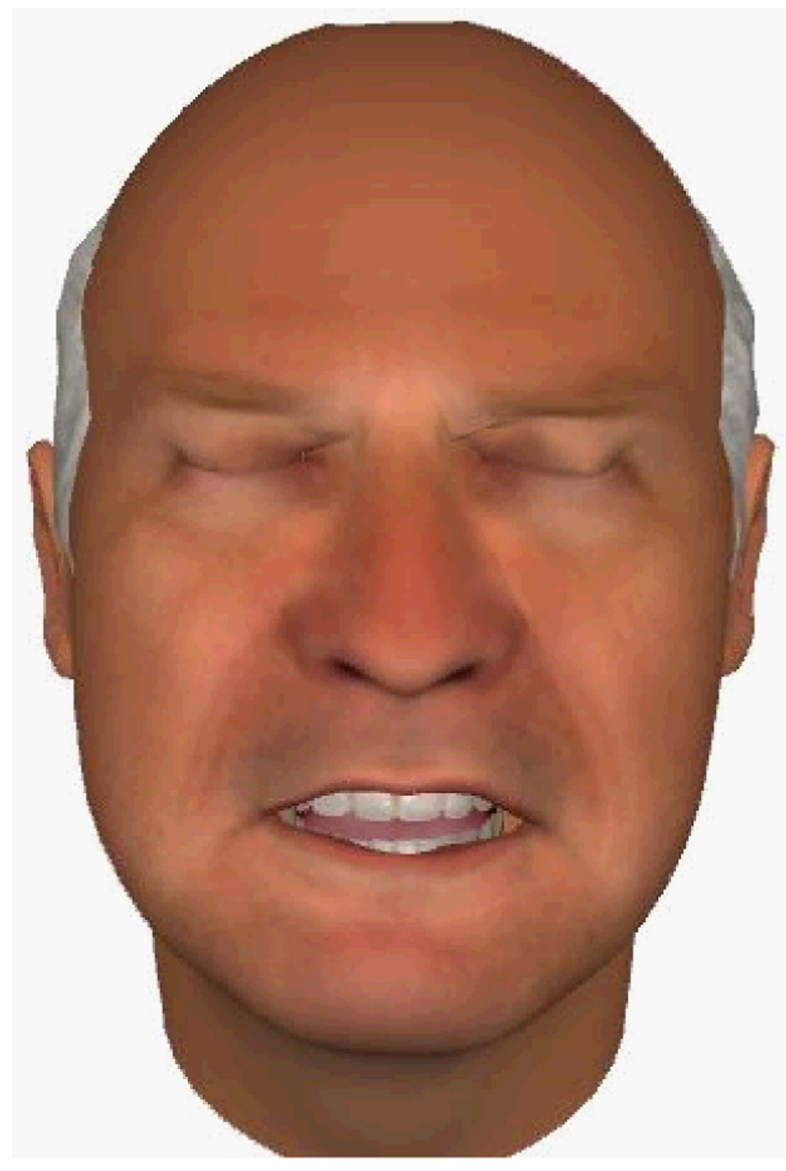

Figure 2 Still frame of a $\mathrm{VH}$ patient displaying high pain. Abbreviation: $\mathrm{VH}$, virtual human. 
The perspective-taking group comprised $49 \%$ of the sample, and $75 \%$ of the participants believed that the VH faces showed realistic depictions of pain. Table 1 shows the full list of demographics.

\section{Questionnaires}

Visual analog scale For each VH, participants made pain management decisions - one pain assessment (pain intensity) and one pain treatment (willingness to administer opioids) rating. Pain ratings were captured through the use of a 100point visual analog scale (VAS). The endpoints of the VAS ranged from "no pain sensation" to "most intense pain imaginable", or "not at all likely" to "complete certainty".

\section{GRAPE}

All of the participants completed the Gender, Race, and Age Pain Expectations (GRAPE) questionnaires, either after reading the perspective-taking vignette or after waiting for the new videos to load for 2 minutes. The Gender Role Expectation

Table I Patient demographics

\begin{tabular}{|c|c|c|}
\hline & $\mathbf{N}$ & $\%$ of total \\
\hline \multicolumn{3}{|l|}{ Sex } \\
\hline Female & 58 & 60 \\
\hline Male & 38 & 40 \\
\hline \multicolumn{3}{|l|}{ Race } \\
\hline Asian & 16 & 17 \\
\hline Black or African-American & 13 & 13 \\
\hline White or Caucasian & 62 & 65 \\
\hline Other & 5 & 5 \\
\hline \multicolumn{3}{|l|}{ Ethnicity } \\
\hline Hispanic & 27 & 28 \\
\hline Not Hispanic & 69 & 72 \\
\hline \multicolumn{3}{|l|}{ Marital status } \\
\hline Single & 92 & 96 \\
\hline Married & 3 & 3 \\
\hline Divorced & I & 1 \\
\hline \multicolumn{3}{|l|}{ Education } \\
\hline Less than high school & I & I \\
\hline High school/GED & 12 & 13 \\
\hline Partial completion of college & 66 & 69 \\
\hline Completion of college & 9 & 9 \\
\hline Partial completion of graduate school & 8 & 8 \\
\hline \multicolumn{3}{|l|}{ Study area } \\
\hline Business & 10 & 10 \\
\hline Health care & 30 & 31 \\
\hline Liberal Arts & 5 & 5 \\
\hline Science & 35 & 37 \\
\hline Other & 14 & 15 \\
\hline Missing or N/A & 2 & 2 \\
\hline \multicolumn{3}{|l|}{ Intervention group } \\
\hline Control & 49 & 51 \\
\hline Perspective-taking & 47 & 49 \\
\hline
\end{tabular}

Abbreviations: GED, General Educational Development; N/A, not applicable. of Pain questionnaire evaluates participants' expectations of the typical man and woman, as well as the participants' own pain sensitivity, endurance, and willingness to report pain. ${ }^{25}$ The Cronbach's alpha for this measure is $\alpha=0.6$. The Race/ Ethnicity Expectations of Pain Questionnaire asks how the typical white, black, Hispanic, and Asian person, as well as the participant, rate pain sensitivity and willingness to report pain. The Cronbach's alpha for this measure is $\alpha=0.7$. The Age Expectations of Pain Questionnaire evaluates the participants' expectations of the typical young adult, middle-aged adult, and older adult, as well as the participants' own pain sensitivity and willingness to report pain. The Cronbach's alpha for this measure is $\alpha=0.75$.

\section{Cognition follow-up questionnaire}

The participants' answered the open-ended question "what were you thinking about during the (control or perspectivetaking) task" immediately after completing the intervention (Figure 1). The open-ended questions were grouped into three categories: 1) mentioning/not mentioning pain intensity; 2) taking/not taking a general perspective-taking point of view; and 3) considering/not considering the VHs' demographic characteristics (sex, race/ethnicity, or age).

\section{Statistical analyses}

SPSS-20 (IBM Corporation, Armonk, NY, USA) was used for all statistical analyses. Descriptive statistical analyses were conducted to summarize the demographic results. A LENS model analysis was also conducted to examine both nomothetic (group-based) and idiographic (individualbased) decision policies. The LENS model is an analog method for capturing how groups of people and individuals use information in their environment to form judgments. The LENS model suggests that judgments are contextually determined. LENS model designs have previously been used to investigate a number of medical and pain decisions. ${ }^{26-28}$ The nomothetic analyses examined two within- and betweensubjects repeated measures analysis of variance (rANOVA) in order to examine pain management decisions made by the participants based on the VHs' personal characteristics. Thus, the rANOVA was a $2(\mathrm{VH}$ sex $) \times 2(\mathrm{VH}$ race $) \times 2(\mathrm{VH}$ age) $\times 2$ (time) $\times 2$ (intervention group) design. At the idiographic level, simultaneous multiple regression equations were generated for each participant to capture his or her decision-making policies. The term "decision policy" refers to the consistent approach an individual takes in weighing contextual cues (eg, VH's sex, race, and age) to make a given decision. VH cues of sex, race, and age were the independent 
variables in each model, and the pain assessment and treatment ratings were the dependent variables in their respective models. The standardized regression coefficients $(\beta)$ in each equation represent the weight of each cue in the formation of the assessment and treatment judgments. The weight represents the unique contribution and relative importance of each cue in the participant's clinical decision. A participant was considered to have a significant cue use if his or her ( $\beta$ ) was significant at $P<0.05$. The number of significant $\beta$ s for each group (perspective-taking vs control group) and demographic cue (sex, race, and age) were tallied and are presented in "Results".

Interrater reliability was tested to examine the agreement between two raters' assessments of the participants' open-ended responses. Fisher's exact tests were conducted to determine whether participants in the perspective-taking group mentioned each topic at a significantly different rate than the control group. Kappas $(\kappa)$ were calculated to evaluate the interrater reliability.

A power analysis also was conducted in order to calculate the number of participants needed for this study. The power analysis was based on the Drwecki et $\mathrm{al}^{14}$ study, which found that employing a short perspective-taking paragraph reduced the influence of race in making pain treatment decisions. One of Drwecki et al's ${ }^{14}$ lowest main effect sizes was a Cohen's $d=0.20$. A Cohen's $d$ of 0.20 is approximately $8 \%$ of the variance. Using a rANOVA - Between-Within design, it was found to have an effect size $f=0.29$ with $\alpha=0.05$, power $=0.80$. Thus, it was necessary to recruit a minimum of 26 participants in order to demonstrate a significant main effect. An additional $20 \%$ were necessary to account for any potential dropouts, which suggested that we need to recruit a minimum total sample of 32 participants. Significantly more participants (96) were actually recruited in order to examine the interactions between the sex, race, and age of the $\mathrm{VH}$ patients and the intervention groups and time (preand postintervention).

\section{Results}

\section{Nomothetic analyses}

Perceived VH patient pain intensity

The main effect of time was significant $(F(1,94)=22.16$, $\left.P<0.001,{ }_{\mathrm{p}} \eta^{2}=0.191\right)$, suggesting that both groups (perspective-taking and control) rated the pain intensity of all VHs higher at postintervention than preintervention. The main effect of group was not significant $(F(1,94)=0.018$, $P=0.90,{ }_{\mathrm{p}} \eta^{2}=0.00$ ), indicating that the groups did not differ in their ratings of pain intensity. The group $\times$ time interaction was also nonsignificant $\left(F(1,94)=0.88, P=0.35,{ }_{p} \eta^{2}=0.01\right)$. Table 2 presents the results for pain intensity.

\section{Willingness to administer opioids}

There was a main effect of time, with participants more willing to administer opioids to all of the VHs at postintervention than at preintervention $\left(F(1,94)=17.96, P<0.001,{ }_{p} \eta^{2}=0.16\right)$. Similar to pain intensity, the main effect of group was not significant, indicating that the groups did not rate willingness to administer opioids significantly differently $(F(1,94)$ $\left.=0.78, P=0.38,{ }_{p} \eta^{2}=0.01\right)$. There was also a nonsignificant group $\times$ time interaction, suggesting that the groups did not differ in their willingness to administer opioids from pre- to postintervention $\left(F(1,94)=0.36, P=0.55,{ }_{\mathrm{p}} \eta^{2}=0.00\right)$. Table 2 presents the results for willingness to administer opioids.

\section{Pain management decisions: sex, race, and age}

This study found a main effect for $\mathrm{VH}$ age as well as a race $\times$ age interaction. Participants assessed older $\mathrm{VH}$ patients to be experiencing greater pain intensity $(F(1,94)=34.10$, $\left.P<0.001,{ }_{\mathrm{p}} \eta^{2}=0.266\right)$ and were more willing to administer opioids to them $\left(F(1,94)=28.93, P<0.001,{ }_{\mathrm{p}} \eta^{2}=0.24\right)$ than to younger $\mathrm{VH}$ patients. The race $\times$ age interaction found that the difference in pain intensity ratings based on race (African-American $\mathrm{VH}$ patients $>$ Caucasian $\mathrm{VH}$ patients) was greater for older than younger $\mathrm{VH}$ patients $\left(F(1,94)=3.95, P=0.05,{ }_{p} \eta^{2}=0.04\right)$. Table 2 presents the pain management decision ratings.

\section{Idiographic analyses Pain intensity}

The results indicate that the use of cues increased from pre- to postintervention; however, this effect was less for the perspective-taking group. For example, 6 participants ( 3 in the control group and 3 in the perspective-taking group) used sex as a cue at preintervention, whereas 14 participants (10 in the control group and 4 in the perspective-taking group) used sex as a cue at postintervention. Similarly, 5 participants ( 2 in the control group and 3 in the perspective-taking group) used race as a cue at preintervention, whereas 8 participants ( 6 in the control group and 2 in the perspective-taking group) used race as a cue at postintervention. Finally, 13 participants ( 8 in the control group and 5 in the perspective-taking group) used age as a cue at preintervention, whereas 18 participants (9 in both the control and perspective-taking groups) used age as a cue at postintervention. Table 3 presents the number of cues used by each group at both pre- and postintervention. 
Table 2 Pain assessment and treatment decisions of for $\mathrm{VH}$ patients

\begin{tabular}{|c|c|c|c|c|}
\hline Decisions & Main effect/interaction & Mean (SE) & $\boldsymbol{F}$ & Partial $\eta^{2}$ \\
\hline \multicolumn{5}{|l|}{ Pain assessment } \\
\hline \multirow[t]{15}{*}{ Pain intensity } & Time & & $22.16 * *$ & 0.19 \\
\hline & Preintervention & $40.11(1.73)$ & & \\
\hline & Postintervention & $45.12(1.73)$ & & \\
\hline & Group & & 0.02 & 0.00 \\
\hline & Perspective-taking & $42.40(2.31)$ & & \\
\hline & Control & $42.83(2.36)$ & & \\
\hline & Sex & & 0.01 & 0.00 \\
\hline & Female & $42.64(39.29)$ & & \\
\hline & Male & $42.59(1.66)$ & & \\
\hline & Race & & 0.90 & 0.01 \\
\hline & White & $42.40(1.66)$ & & \\
\hline & Black & $42.83(1.67)$ & & \\
\hline & Age & & $34.10 * *$ & 0.27 \\
\hline & Young & $40.75(1.62)$ & & \\
\hline & Old & $44.48(1.74)$ & & \\
\hline \multirow[t]{20}{*}{ Two-way interaction } & Group $\times$ time & & 0.88 & 0.01 \\
\hline & Control preintervention & $39.40(2.42)$ & & \\
\hline & Control postintervention & $45.40(2.43)$ & & \\
\hline & Perspective-taking preintervention & $40.83(2.37)$ & & \\
\hline & Postintervention perspective-taking & $44.84(2.48)$ & & \\
\hline & Sex $\times$ race & & 0.05 & 0.00 \\
\hline & Female Caucasian & $42.47(1.72)$ & & \\
\hline & Female black & $42.81(1.70)$ & & \\
\hline & Male Caucasian & $43.06(1.74)$ & & \\
\hline & Male black & $47.17(1.8)$ & & \\
\hline & Sex $\times$ age & & 0.00 & 0.00 \\
\hline & Female young & $40.77(1.66)$ & & \\
\hline & Female old & $44.5 \mathrm{I}(\mathrm{I} .80)$ & & \\
\hline & Male young & $40.74(1.64)$ & & \\
\hline & Male old & $44.44(1.73)$ & & \\
\hline & Race $\times$ age & & $3.95 * *$ & 0.04 \\
\hline & White young & $40.83(1.61)$ & & \\
\hline & White old & $43.96(1.78)$ & & \\
\hline & Black young & $40.67(1.67)$ & & \\
\hline & Black old & $44.99(1.74)$ & & \\
\hline \multicolumn{5}{|l|}{ Pain treatment } \\
\hline \multirow[t]{15}{*}{ Administer opioid analgesics } & Time & & $17.96 * *$ & 0.16 \\
\hline & Preintervention & $32.00(2.13)$ & & \\
\hline & Postintervention & $35.83(2.20)$ & & \\
\hline & Group & & 0.78 & 0.01 \\
\hline & Perspective-taking & $32.59(2.99)$ & & \\
\hline & Control & $36.26(2.93)$ & & \\
\hline & Sex & & 0.18 & 0.00 \\
\hline & Female & $34.29(2.12)$ & & \\
\hline & Male & $34.53(2.10)$ & & \\
\hline & Race & & 0.09 & 0.00 \\
\hline & White & $34.35(2.09)$ & & \\
\hline & Black & $34.48(2.12)$ & & \\
\hline & Age & & $28.93 * *$ & 0.24 \\
\hline & Young & $32.45(2.13)$ & & \\
\hline & Old & $36.38(2.11)$ & & \\
\hline \multirow[t]{5}{*}{ Two-way interaction } & Group $\times$ time & & 0.36 & 0.00 \\
\hline & Control preintervention & $33.50(2.99)$ & & \\
\hline & Control postintervention & $39.01(3.08)$ & & \\
\hline & Perspective-taking preintervention & $30.49(3.05)$ & & \\
\hline & Perspective-taking postintervention & $34.64(3.14)$ & & \\
\hline
\end{tabular}


Table 2 (Continued)

\begin{tabular}{|c|c|c|c|c|}
\hline Decisions & Main effect/interaction & Mean (SE) & $\boldsymbol{F}$ & Partial $\eta^{2}$ \\
\hline & Sex $\times$ race & & 0.16 & 0.00 \\
\hline & Female Caucasian & $34.14(2.14)$ & & \\
\hline & Female black & $34.44(2.15)$ & & \\
\hline & Male Caucasian & $34.55(2.10)$ & & \\
\hline & Male black & $34.52(2.14)$ & & \\
\hline & Sex $\times$ age & & 0.17 & 0.00 \\
\hline & Female young & $32.40(2.18)$ & & \\
\hline & Female old & $36.19(2.15)$ & & \\
\hline & Male young & $32.49(2.14)$ & & \\
\hline & Male old & $36.57(2.14)$ & & \\
\hline & Race $\times$ age & & 1.14 & 0.01 \\
\hline & White young & $32.56(2.12)$ & & \\
\hline & White old & $36.13(2.15)$ & & \\
\hline & Black young & $32.33(2.18)$ & & \\
\hline & Black old & $36.63(2.12)$ & & \\
\hline
\end{tabular}

Notes: Degrees of freedom were I, 94 for all main effects and interactions. $* * P<0.0$ I.

Abbreviations: $\mathrm{SE}$, standard error; $\mathrm{VH}$, virtual human.

\section{Willingness to prescribe opioids}

Similar to pain intensity, the results indicate that the use of cues increased from pre- to postintervention, but these results were less in the perspective-taking group. At preintervention, 6 participants ( 3 in the control group and 3 in the perspectivetaking group) used sex as a cue, whereas 13 participants ( 8 in the control group and 5 in the perspective-taking group) used this cue at postintervention. Two participants ( 1 in the control group and 1 in the perspective-taking group) used race as a cue at preintervention, whereas 6 participants ( 5 in the control group and 1 in the perspective-taking group) used race as a cue at postintervention. Finally, 15 participants ( 7 in the control group and 8 in the perspective-taking group) used age as a cue, whereas 21 people (10 in the control group and 11 in the perspective-taking group) used age as a cue at postintervention. Table 3 presents the number of cues used by each group at both pre- and postintervention.

\section{Cognitions during the open- ended question}

\section{Pain}

A majority of the participants in the perspective-taking group mentioned pain (94\%) in their responses, while only a minority of participants completing the control group questions mentioned pain (41\%). A Fisher's exact test found that the responses between the groups were statistically significant, $P<0.001$. The interrater reliability for the participants' mentioning pain in their open-ended answers was $\kappa=0.93, P<0.001$.

\section{General perspective-taking}

Approximately $74 \%$ of participants in the perspective-taking group took a general perspective-taking point of view; however, only $6 \%$ of the control group took a perspectivetaking point of view. This suggests that the perspectivetaking intervention was more effective in manipulating the participants' perspective. An example of one participant's general perspective-taking response was

"I believe the patient is experiencing a lot of desperate hope. They are tired of their pain. The patient would be very anxious about the prescription of medication and whether it would help decrease their chronic pain.”

A Fisher's exact test found that the responses between the two intervention groups was statistically significant $(P<0.001)$. The interrater reliability for writing about general perspectivetaking in the open-ended answers is $\kappa=0.83, P<0.001$.

\section{Patient demographics}

Only $4 \%$ of the participants in the perspective-taking group mentioned the consideration of the sex, race, or age of the $\mathrm{VH}$ when reading the perspective-taking paragraphs, while $33 \%$ of the participants in the control group reported thinking about

Table 3 Cue use across group at pre- and postintervention

\begin{tabular}{|c|c|c|c|c|}
\hline & \multicolumn{2}{|c|}{ Preintervention } & \multicolumn{2}{|c|}{ Postintervention } \\
\hline & $\begin{array}{l}\text { Control } \\
\text { group }\end{array}$ & $\begin{array}{l}\text { Perspective- } \\
\text { taking group }\end{array}$ & $\begin{array}{l}\text { Control } \\
\text { group }\end{array}$ & $\begin{array}{l}\text { Perspective- } \\
\text { taking group }\end{array}$ \\
\hline \multicolumn{5}{|c|}{ Pain intensity } \\
\hline Sex & 3 & 3 & 10 & 4 \\
\hline Race & 2 & 3 & 6 & 2 \\
\hline Age & 8 & 5 & 9 & 9 \\
\hline \multicolumn{5}{|c|}{ Willingness to administer opioids } \\
\hline Sex & 3 & 3 & 8 & 5 \\
\hline Race & 1 & 1 & 5 & 1 \\
\hline Age & 7 & 8 & 10 & 11 \\
\hline
\end{tabular}


those characteristics when they read the control sentences. A Fisher's exact test found that the difference in the responses between the groups was statistically significant, $P<0.001$. The interrater reliability for considering the sex, race, or age of the patient when reading the intervention paragraphs is $\kappa=0.83, P<0.001$.

\section{Discussion}

Overall, the results of this study demonstrate the utility of a virtual technology intervention in the measurement of pain management decisions. Recent studies have found that perspective-taking is an effective component of pain management. ${ }^{14}$ This study extended the research in several ways. First, the study examined whether participating in a perspective-taking intervention vs a control group modifies pain management decisions. Second, this was the first online study using VH technology to examine the effect of a perspective-taking intervention. The advantage of an online study is that a large number of participants are able to complete the study at their convenience. And third, we inquired about intervention-related cognitions during the assessment, which allowed for enhanced understanding of the nomothetic and idiographic results.

Overall, results indicated that the number of cues used by a participant to make pain management decisions increased for both groups (perspective-taking and control) from pre- to postintervention. The idiographic results, however, suggest that the increase in cue use at postintervention was mitigated by the participant's participation in the perspective-taking treatment group. More specifically, participants in the perspective-taking group used fewer cues than the control group at postintervention. Although speculative, taking the perspective of another person could have accounted for these findings.

Interestingly, the study also found that both the perspective-taking and control groups' pain ratings increased from pre- to postintervention. The increase in pain ratings and use of cues for both groups could have resulted from several reasons. First, the perspective-taking group's pain management ratings and cue use may have increased due to enhanced empathy. The results of the cognition followup questionnaire corroborate this as a possible explanation since the perspective-taking group was more likely to indicate that they were taking the perspective of the patient after their intervention, compared to the control group. Since the perspective-taking group was more engaged in taking the general perspective of another, it is possible that participants' empathy for the VHs (regardless of the patient's sex, race, or age) increased after the intervention, thus leading to the observed postintervention increase in pain management ratings and use of cues. However, since empathy was not formally assessed in this study, future studies should incorporate empathy into those studies in order to confirm this hypothesis.

In addition, although both groups completed the GRAPE questionnaires prior to their respective interventions, the control group's ratings and cue use may have increased as a result of their waiting for the videos to load, which may have allowed them more time to reflect on the Gender, Race, and Age Pain Expectations Questionnaires items (ie, whether they considered how the demographic characteristics of a patient impacted the perception of his or her pain) than the perspective-taking group. This may be a possible explanation of why the ratings changed, because the GRAPE questionnaire asks the participants to consider how a typical demographic group (eg, sex, race, or age) manage their pain, which likely requires the participants to think more about how specific groups of patients cope with pain than they usually do. ${ }^{29}$ However, the GRAPE has never been formally studied to determine whether it may serve as an intervention in and of itself. In support of this hypothesis, the cognition follow-up questionnaire's answers suggest that the control group was thinking more about the sex, race, and age differences than the perspective-taking group.

A final explanation is that the scores and cue use for both groups may have increased because engaging in the VH exercise may have itself served as a perspective-taking task. Hence, through an additional exposure to the VH task, all participants could have more easily identified with and related to the VHs' pain, thus leading to modification in pain management decisions.

It is possible that these explanations for the findings could be occurring simultaneously, which could suggest why the nomothetic results did not result in many significant findings. However, the success of the perspective-taking task was more likely captured through the use of idiographic analyses and open-ended questions. However, in order to more thoroughly examine this explanation in the future, it will be important to power the study for the idiographic results and to randomize the participants to either completing or not completing the GRAPE questionnaire.

\section{Implications of the study}

Overall, the study findings suggest that individuals' perceptions of others' pain and their pain management ratings can be altered. Regardless of why the cue use and ratings increased postintervention, the increase in ratings is important. It is 
possible that an online intervention using a combination of techniques may help to reduce the discrepancy between the patient's and the observer's pain management ratings and should be further examined in the future.

Since the pain intensity and treatment ratings in this study increased from pre- to postintervention, a perspective-taking intervention or an intervention in which time is given to reflect on the VHs could be used as an online educational tool to modify assessment and treatment decisions. The procedures used in this study might also help health care providers to develop more empathy such that they would be more likely to rate a patient's pain similar to how the patient would rate it.

Although the effect sizes for the group were modest, the results can still have a large impact on health care. Laypeople, especially caregivers, coaches, and future health care trainees and providers, are responsible for identifying pain in people in the community. If they are unable to accurately identify and assess pain, then individuals with acute or chronic pain may receive inadequate care. Since health care professionals typically see thousands of patients during the course of their careers, programs should consider using brief, empathy-encouraging educational interventions to enhance effectiveness in the assessment and treatment of pain across patients of varying sex, race, and age cohorts.

\section{Limitations}

Participants were primarily laypeople (eg, students) instead of health care professionals; therefore, it is unclear how the results will generalize to a health care population. However, previous VH research has shown that laypeople's pain management decisions are similar to those of medical providers. Similar to most studies conducted in a university setting, the participants in this study also were relatively homogenous. Therefore, the effects of the perspective-taking intervention may vary if tested in different ethnic, age, or education groups. Finally, it is possible that some participants were able to determine the intent of the study and thus adjusted their responses in a socially desirable manner. Although this is presented here as a limitation, it should be noted that nearly all training on diversity conducted in academic settings is done so in a highly face valid manner and is subject to the same social desirability concerns.

\section{Future studies}

While the participants in this study were solely laypeople, it remains important to determine whether a perspective-taking or other intervention can reduce the influence of sex, race, or age cue use (that has been reported in previous studies) on health care trainees and professionals. Second, future perspective-taking research should evaluate the necessary dose of a perspective-taking treatment and combination of techniques needed to reduce discrepancies in treatment. For example, a study should compare a control group, a perspective-taking group similar to this study, and an immersive perspective-taking group to determine which type of intervention is the most effective in improving pain management decisions. Third, future perspective-taking studies should include VHs that are expressing both high and low pain expressions. It is possible that this study found that fewer demographic cues were used in this population due to participants not having to distinguish between high and low pain in the VH patients. Future studies also should examine whether an increase in the pain management ratings actually means that pain management accuracy is increasing or rather whether the pain intensity and willingness to administer opioids is being overstated. Finally, the idiographic results from this study warrant having future perspective-taking studies power their studies based on idiographic analyses to more thoroughly examine significant differences within the idiographic results.

\section{Conclusion}

In sum, the nomothetic results suggest that a simple, brief perspective-taking intervention provided no additional effect on sex, race, and age cue use. At the same time, the results do suggest that engaging in a task that exposes individuals to diverse virtual patients may increase awareness or empathy for patients, with resulting increases in their ratings of VH pain and demographic cue use. The idiographic results suggest that a perspective-taking task appears to mitigate the use of cues at postintervention. These results suggest that a brief intervention may alter participants' pain assessment and treatment ratings. Future research is warranted to determine how health care trainees and health care professionals respond to an online perspective-taking intervention and what dose of a perspective-taking treatment and combination of techniques are needed to reduce discrepancies in treatment.

\section{Acknowledgment}

Supported by the National Institute of Dental and Craniofacial Research (R01DE013208) to Dr Michael E Robinson.

\section{Disclosure}

The authors report no conflicts of interest in this work. 


\section{References}

1. Turk DC, Melzack R, editors. The measurement of pain and the assessment of people experiencing pain. In: Handbook of Pain Assessment. 3rd ed. New York, NY: Guilford Press; 2011.

2. Fillingim RB, King CD, Ribeiro-Dasilva MC, Rahim-Williams B, Riley JL. Sex, gender, and pain: a review of recent clinical and experimental findings. J Pain. 2009;10(5):447-485.

3. Robinson ME, Riley JL, Myers CD, et al. Gender role expectations of pain: relationship to sex differences in pain. J Pain. 2001; 2(5):251-257.

4. Edwards CL, Fillingim RB, Keefe F. Race, ethnicity, and pain. Pain. 2001;94:133-137.

5. Gauthier LR, Gagliese L.Assessment of pain in older persons. In: Turk DC, Melzack R, editors. Handbook of Pain Assessment. 3rd ed. New York, NY: Guilford Press; 2011.

6. Herman AD, Johnson TM, Ritchie CS, Parmelee PA. Pain management interventions in the nursing home: a structured review of the literature. J Am Geriatr Soc. 2009;57:1258-1267.

7. Olsen Y, Daumitt GL, Ford DE. Opioid prescriptions by US primary care physicians from 1992 to 2001. J Pain. 2006;7(4):225-235.

8. Pletcher MJ, Kertesz SG, Kohn MA, Gonzales R. Trends in opioid prescribing by race/ethnicity for patients seeking care in US emergency departments. JAMA. 2008;299(1):70-78.

9. Tamayo-Sarver JH, Dawson NV, Hinze SW, et al. The effect of race/ethnicity and desirable social characteristics on physicians' decisions to prescribe opioid analgesics. Acad Emerg Med. 2003;10(11):1239-1248.

10. Gauthier LR, Gagliese, L. Assessment of pain in older persons. In: Turk DD, Melzack R, editors. Handbook of Pain Assessment. 3rd ed. New York, NY: Guilford Press; 2011:242-259.

11. Horgas AL, Elliott AF. Pain assessment and management in persons with dementia. Nurs Clin North Am. 2004;39:593-606.

12. IPRCC. National Pain Strategy: A Comprehensive Population Health Level Strategy for Pain. Services DoHaH. Bethesda, MD: NIH; 2015.

13. Blatt B, LeLacheur SF, Galinsky AD, Simmens SJ, Greenberg L. Does perspective-taking increase patient satisfaction in medical encounters? Acad Med. 2010;85(9):1445-1452.

14. Drwecki BB, Moore CF, Ward SE, Prkachin KM. Reducing racial disparities in pain treatment: the role of empathy and perspective-taking. Pain. 2011;152:1001-1006.

15. Todd AR, Bodenhausen GV, Galinsky AD. Perspective taking combats the denial of intergroup discrimination. J Exp Soc Psychol. 2012;48:738-745.
16. Filichia L, Halan S, Blackwelder E, et al. Description of web-enhanced virtual character simulation system to standardize patient hand-offs. J Surg Res. 2011;166(2):176-181.

17. Stevens A, Hernandez J, Johnsen K, et al. The use of virtual patients to teach medical students history taking and communication skills. $\mathrm{Am}$ J Surg. 2006;191(6):806-811.

18. Hirsh AT, George SZ, Robinson ME. Pain assessment and treatment disparities: a virtual human technology investigation. Pain. 2009;143: 106-113.

19. Wandner LD, Stutts LA, Alquadah AF, et al. Virtual human technology: patient demographics and healthcare training factors in pain observation and treatment recommendations. J Pain Res. 2010;3:241-247.

20. Stutts LA, Hirsh AT, George SZ, Robinson ME. Investigating patient characteristics on pain assessment using virutal human technology. Eur J Pain. 2010;14(10):1040-1045.

21. Hirsh AT, Alquadah AF, Stutts LA, Robinson ME. Virtual human technology: capturing sex, race, and age influences in individual pain decision policies. Pain. 2009;140:231-238.

22. Bartley EJ, Boissoneault J, Vargovich AM, et al. The influence of healthcare professional characteristics on pain management decisions. Pain Med. 2014;16(1):99-111.

23. Wandner LD, Hirsh AT, Torres CA, et al. Using virtual human technology to capture dentists' decision policies about pain. J Dental Res. 2013;92(4):301-305.

24. Prkachin KM. The consistency of facial expressions of pain: a comparison across modalities. Pain. 1992;51:297-306.

25. Wandner LD, Scipio CD, Hirsh AT, Torres CA, Robinson ME. The perception of pain in others: how gender, race, and age influence pain expectations. J Pain. 2012;13(3):220-227.

26. Hirsh AT, Alqudah AF, Stutts LA, Robinson ME. Virtual human technology: capturing sex, race, and age influences in individual pain decision policies. Pain. 2008;140(1):231-238.

27. Wigton RS. Applications of judgement analysis and cognitive feedback to medicine. In: Brehmer B, Joyce, CRB, editors. Human Judgement: The SJT View. Amsterdam, Netherland: Elsevier; 1988.

28. Wigton RS. Social judgement theory and medical judgement. Think Reas. 1996;2(175):175-190.

29. Wandner LD, Scipio CD, Hirsh AT, Torres CA, Robinson ME. The perception of pain in others: how gender, race, and age influence pain expectations. J Pain. 2012;13(3):220-227.
Journal of Pain Research

\section{Publish your work in this journal}

The Journal of Pain Research is an international, peer-reviewed, open access, online journal that welcomes laboratory and clinical findings in the fields of pain research and the prevention and management of pain. Original research, reviews, symposium reports, hypothesis formation and commentaries are all considered for publication.

\section{Dovepress}

The manuscript management system is completely online and includes a very quick and fair peer-review system, which is all easy to use. Visit http://www.dovepress.com/testimonials.php to read real quotes from published authors. 